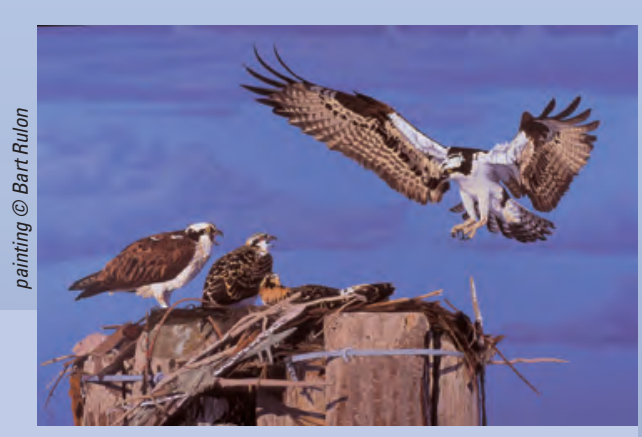

\title{
Ospreys in Oregon and the Pacific Northwest
}

\section{A Bridge to the Wild}

From early April through September each year, famous residents grace the small western town of Corvallis, Oregon. Two ospreys have become mascots of the town since the pair's arrival in 1994. Their nest, built on a 90-foot power pole near the twin bridges over the Willamette River, could be seen by many commuters on their way in and out of town. After the 2002 nesting season, the nest was moved a short distance downriver to a constructed nesting platform because sticks sometimes dropped from the huge nest onto power lines below and caused power outages. At the new location, the pair can once again raise a family of young, their general well being monitored by the 50,000 residents of the community.

\section{Background}

The osprey, often mistakenly called the fish hawk or fish eagle, was first documented in Oregon in 1855 . Historically, ospreys were reported as numerous, nesting in forested areas near water because they favored dead trees or trees with flat or dead tops. Ospreys drastically declined in abundance through the mid-1970's as a side effect of pesticide use, but they have recovered and become a common nesting species along the lower Columbia and Willamette Rivers. Ospreys recently have adapted to primarily depend on power poles, cellular towers, channel markers, and similar structures for nesting sites because suitable natural nest sites (trees) are scarce. The number of pairs nesting along the Willamette River between Eugene and Portland increased from 13 pairs in 1976 to 78 pairs in 1993, and increased again to 234 pairs in 2001. Elsewhere in North America, osprey populations are following the same trend. Unlike most birds of prey, ospreys are tolerant of human activities and will build nests on almost any suitable structure close to water with an abundant supply of fish.

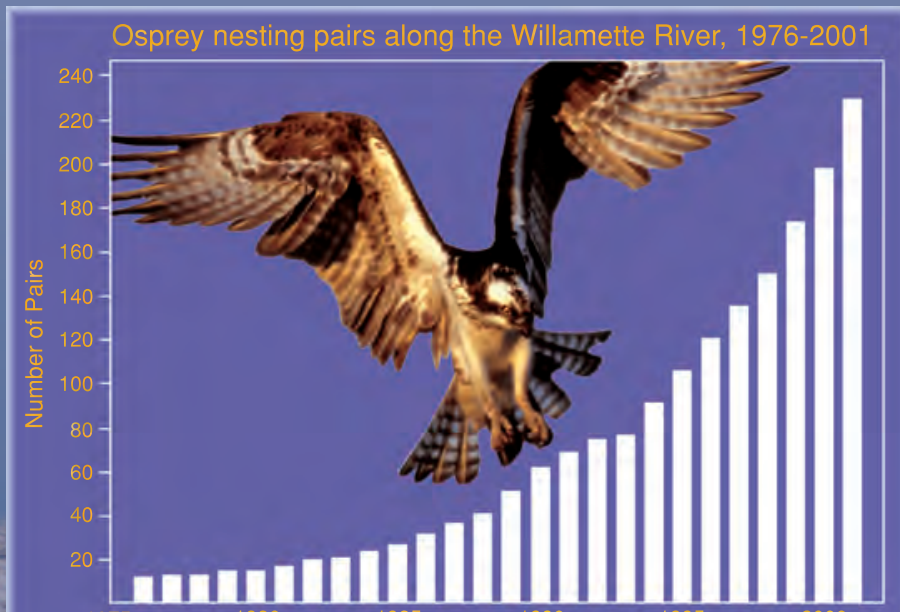

The Osprey

Class: Aves

Order: Falconiformes

Family: Accipitridae

Genus and species: Pandion haliaetus (Latin, sea eagle)

\section{Identification:}

Dark brown above, white below, with white head and prominent dark eye stripe. In flight, crooked wings are distinctive. Call is a series of loud, sharp whistles.

\section{Body Size:}

Weight: 2.5 - 4.5 pounds (1,200-1,900 grams); wingspan: $\sim 56$ inches (142 centimeters).

\section{Distribution:}

Worldwide; in

Oregon around

large rivers,

lakes, estuaries and reservoirs.

\section{Legal Status:}

Protected under

Migratory Bird

Treaty Act of

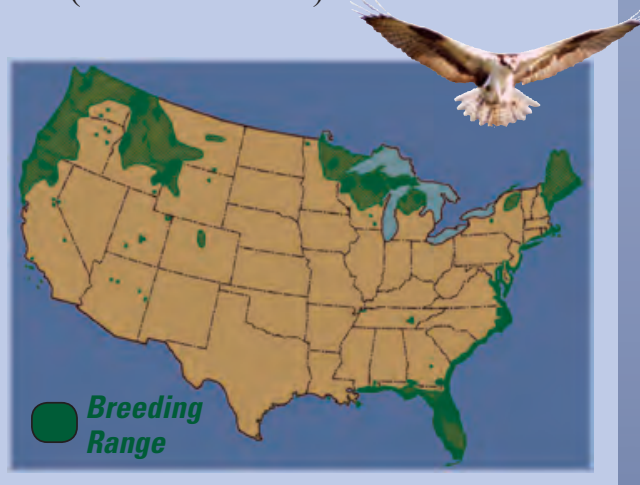

1918 (as amended) ; not endangered or threatened under

U.S. Endangered Species Act.

\section{Nest Size:}

An average-sized nest measured in Corvallis, Oregon weighed 264 pounds (120 kilograms) and was 41 inches (104 centimeters) in diameter.

\section{Eggs:}

Range 1-4, usually 3; creamy white, slightly larger than chicken egg, and heavily blotched with dark brown; hatch in about 38 days.

\section{Diet:}

$99+\%$ fish; plunges into water feet first using a reversible front talon

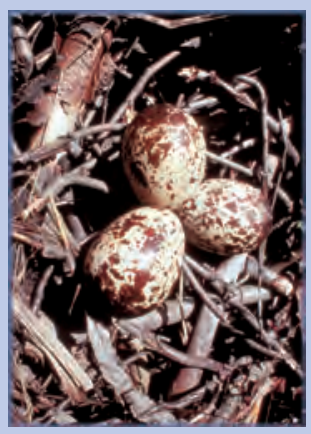
and foot pads with tiny impaling spines (spicules) for grasping slippery fish.

\section{Lifespan:}

Maximum 25 years in the wild. 
Most of the fish (83\%) caught by osprey in the Willamette River in 1993 were largescale suckers, which are numerous and undesirable to anglers. Ospreys are able to catch these fish (usually in shallow, clear water) by hovering and then plunging up to 3 feet ( 1 meter) into the water to capture the fish. Their dense, oily feathers make them well suited to repel water and quickly regain flight. The male brings fish to the female throughout the incubation and nestling periods, and also shares a small portion of the incubation duties. The female remains in nearly constant contact with the chicks until they are about 35-40 days old. She then leaves the nest more often to perch nearby, and occasionally shares hunting duties with the male until the chicks are able to fly at about the age of 52 days. An osprey pair raising two nestlings consumes about 375 pounds (170 kilograms) of fish during the breeding season. This means that the 234 pairs found along the Willamette River in 2001 probably consumed 88,000 pounds (40,000 kilograms) of fish during their six-month nesting season in Oregon, before they migrated south to wintering grounds during late August or September.

\begin{tabular}{|c|}
\hline Osprey Nesting Chronology, Willamette Valley, Oregon \\
\hline 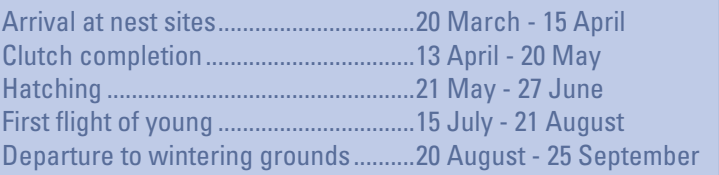 \\
\hline
\end{tabular}

\section{Ospreys and Contaminants}

Ospreys are at the top of the aquatic food chain, and are thus exposed to many pollutants found in the environment. Toxic chemicals are present in water, air, sediments, and aquatic biota throughout osprey breeding and wintering ranges. Many of these contaminants bioconcentrate from water passed through fish gills, and bioaccumulate in the fish from their food. The efficient transfer of chemicals from food to consumer through two or more trophic levels results in biomagnification, a systematic increase in tissue residue concentrations from one trophic level to another. Residues of some organochlorine insecticides, polychlorinated biphenyls (PCBs), dioxins, and furans, have been found in the Willamette River and are potentially toxic to fish, wildlife, and humans. DDT, a well-known pesticide, breaks down to form DDE, which causes eggshells to thin and be easily broken, even under the female's tender care. Because of eggshell thinning, osprey productivity decreased in the 1950's and 1960's, causing populations to decline dramatically until the ban of DDT in 1972. Osprey populations have recovered noticeably due to reduced DDE levels in the environment, increased respect and appreciation of raptors by the public, and their recent adaptation to human-made structures for nest sites.

\section{Ospreys as Biological Indicators}

Why are ospreys good biological indicators of ecosystem health?

- long-lived and top predators of aquatic food webs

- $99+\%$ of diet is fish captured near the nest site

- each pair mates for life and returns to the same nest annually

- single nests are often distributed at regular intervals along rivers and sometimes in colonies near

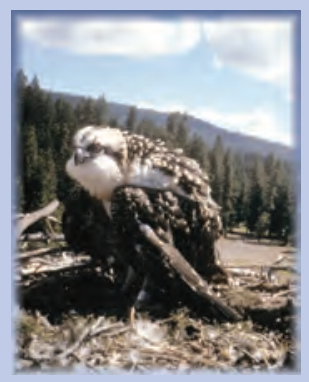
estuaries with abundant fish populations

- often build large, visible nests on accessible structures

- tolerate short-term disturbance at nest site

These traits allow researchers to quickly locate nests at strategic sites, such as above and below urban areas, industrial sites, and dams, and remove a sample egg. The egg serves as a snapshot of contaminants in the female osprey's body at the time the egg formed. For example, chemical analysis of osprey eggs collected from the Columbia River in 1997 and 1998 show eggs with higher levels of PCBs came from nests below Bonneville Dam. Several years later, a dumpsite of electrical equipment containing PCBs was discovered in the Columbia River near the dam.

Charles Henny, James Kaiser, and Robert Grove, with the U.S. Geological Survey (USGS), initiated detailed studies along the Willamette (1993) and lower Columbia River (1995) to evaluate contaminants in osprey eggs and determine if ospreys could be used as biological indicators for long-term monitoring of contaminants and general health of rivers. Initial studies funded by the USGS Biomonitoring Environmental Status and Trends (BEST) Program focused on studies of contaminants in fish; however, because the biomagnification rate of different contaminants from fish to fish-eating birds varies tremendously, ospreys are now being tested for the program. Initial findings, based on data collected along the Willamette River in 1993, show that some contaminants biomagnify from fish to an osprey egg by a factor of 200 or more, whereas others show considerably less biomagnification. Therefore, data describing contaminant residues from fish alone are of limited use in evaluating possible contaminant effects on ospreys or other fish-eating birds. The biomagnification rate (fish to osprey egg) is critical when interpreting the relationship between residue levels in fish and effects of contaminants on ospreys. Research is underway in Oregon and Washington to better understand these relationships.

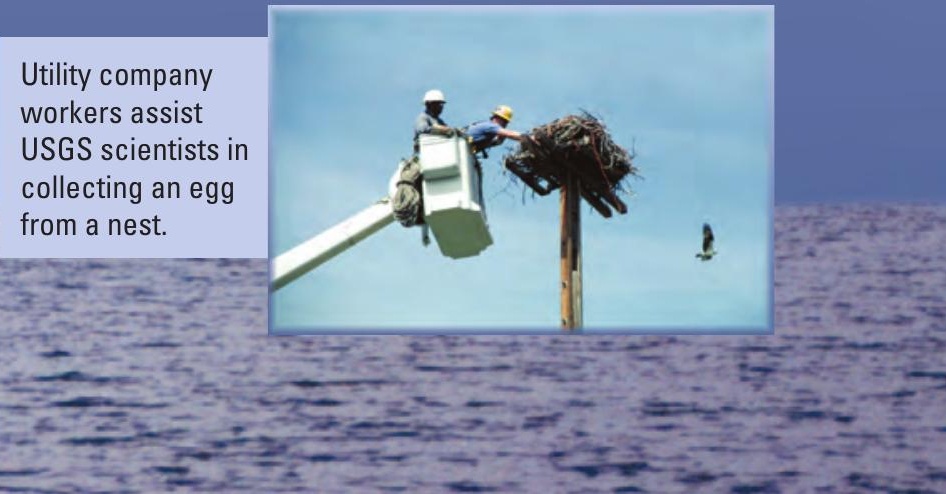




\section{Use of Power Poles}

The rapid osprey population increase along the Willamette River during the past decade has resulted in about 25 new nesting pairs each year, with most nests built at power pole sites ( $74 \%$ of occupied nests in 2001). The large stick nests are primarily built on top of double-crossarm power poles at irrigation pumps in agricultural fields near the river. The bulky nests often cause power outages when sticks interfere with electrical equipment. Also, the electrocution potential is extreme for ospreys when building new nests or perching on power poles. This is because the osprey's nearly 5-foot ( 1.5 meter) wingspan can complete the circuit between either closely spaced energized equipment or between one energized wire and one neutral or ground wire.

(Photo A).

Utility companies use several remedial actions to resolve power outages and electrocution problems while accommodating nesting osprey. Actions include building an alternate nesting platform above the power pole wires (Photo B) or installing a taller, non-energized pole with nesting platform nearby (Photo C). Sometimes, the nest is left undisturbed and insulated jumper wires are added to isolate the nest from energized wires and equipment (Photo D). It is important to cover all energized equipment at or near the nest to prevent electrocutions and outages. These practices are best implemented between September 15 and March 31

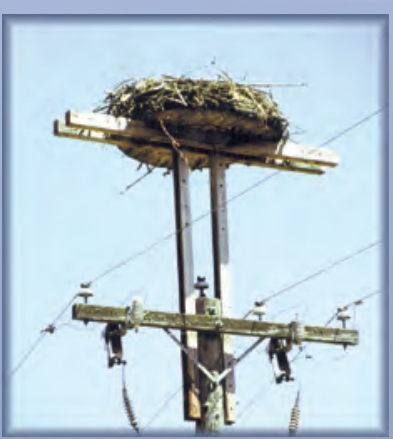

Photos B (above) \& C (right)

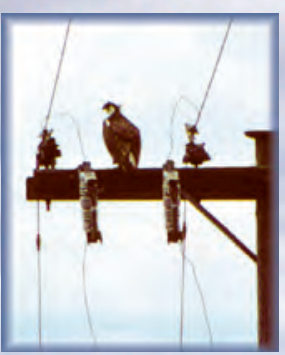

Photo A helpful in preventing outages during the short term. The remedial actions have resulted in a sharp decline of osprey at unsafe power pole sites during the past decade (Figure 1).

Ospreys readily accept alternate nesting platforms, especially if a few armloads of sticks from the old nest are scattered on the new platform.

Attempts to deter osprey from nesting at a chosen site without providing an alternate nesting platform

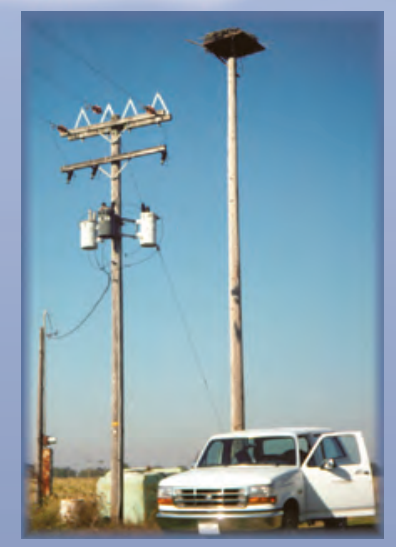
are rarely successful because ospreys have tenacious nest site fidelity. Effective nest deterrent devices are a vital component of any nest relocation project and are used to encourage nesting pairs to accept the alternate platform structure. Several different devices have been used in attempts to prevent nest building on power poles, some of which are more effective than others (Photos $\mathbf{E}$ and $\mathbf{F}$ ).

USGS scientists, in collaboration

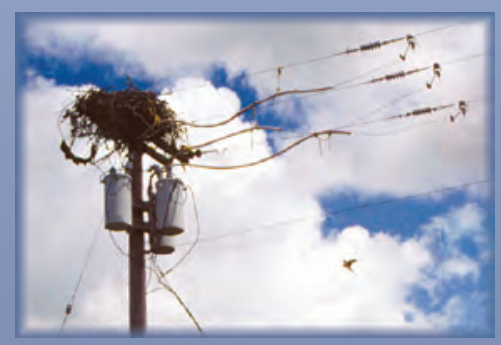

Photo D with local utility companies and the Avian Power Line Interaction Committee, are evaluating nest management strategies and osprey electrocution rates in the Willamette Valley. The results should prove valuable for managing osprey use of power poles for nesting sites throughout the osprey's breeding range.

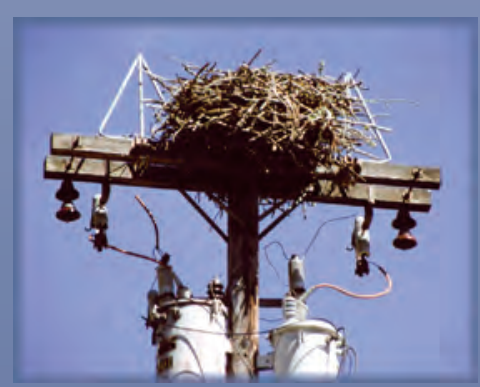

Photo E

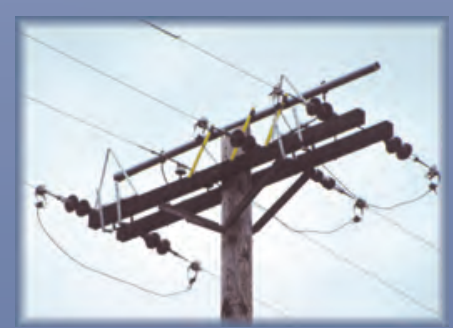

Photo F

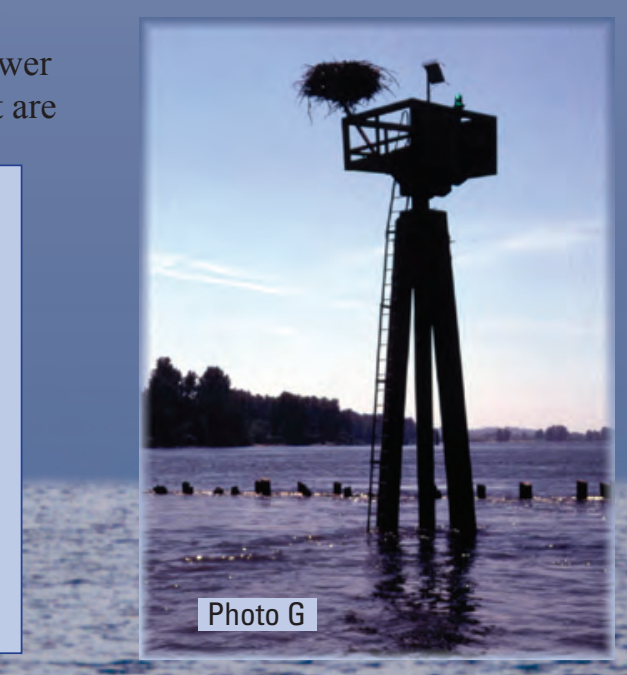

\section{Use of Channel Markers} also increased along the lower 286 miles (460 kilometers) of the Columbia River. In 1998, about 40 percent of approximately 100 occupied osprey nests along the river were built on channel markers. Some of these nests obstructed navigation lights. The U.S. Coast Guard, which is responsible for maintaining navigation structures, is accommodating osprey by constructing lateral nest platforms away from lights (Photo G).
The osprey population has to avoid disturbing nesting osprey. Brief visits to the power pole nests to trim sticks away from electrical equipment are

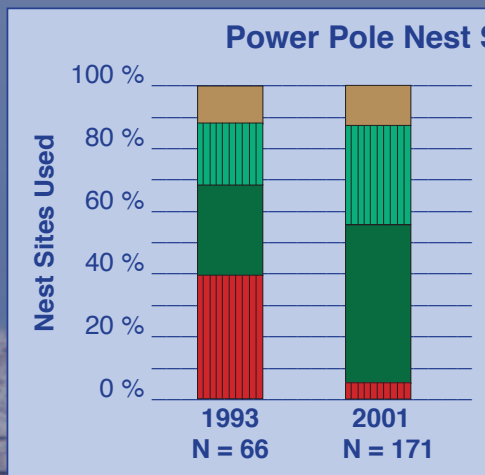

Transmission tower Non-energized pole with platform

Energized pole with platform

Energized pole - not modified 


\section{Osprey Migration Patterns}

Scientists study the migration routes of adult osprey from nest sites in western Oregon to wintering grounds by temporarily attaching small transmitters (1.15 ounces; $30-35$ grams)

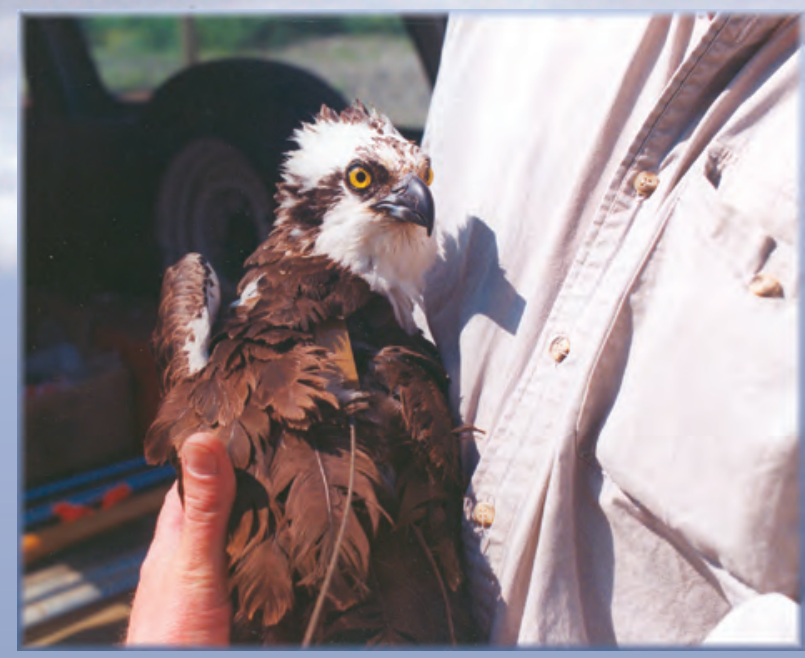

An osprey fitted with a temporary transmitter for tracking its migration via satellite (note: antenna on back).

to ospreys and tracking their movements with satellite receivers. Members of adult osprey pairs migrate separately and winter at different locations, reuniting each spring at the nest after a six-month hiatus. Thirteen ospreys have been tracked to southern Mexico, one to El Salvador, and one to Honduras, each following its own route annually. Many osprey winter in coastal areas like Mazatlan and Puerto Vallarta. Ospreys nesting in other parts of the United States winter farther south into Central and South America. The World-Wide Web makes it possible for the results of the osprey satellite tracking to be widely available through

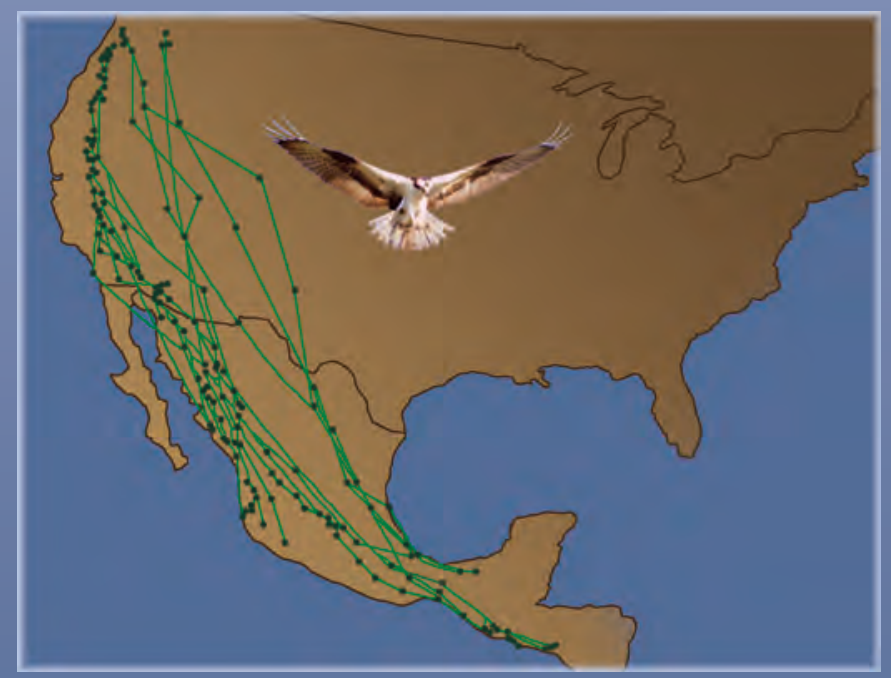

The annual migration of osprey has been traced from Oregon and Washington to various locations in Southern Mexcio and Central America.

This fact sheet and others are available at http://fresc.usgs.gov/. Additional copies available by contacting fresc_outreach@usgs.gov or 541-750-1030 an educational program called "Highway to the Tropics" (http://www.raptor.cvm.umn.edu). The program is designed for teachers and schoolchildren but has valuable information about migrating raptors for anyone interested in the subject.

\section{A Beneficial Coexistence}

Charismatic, adaptable wildlife that live in close proximity to humans, like the osprey, motivate people to care about their natural world. Research reveals that ospreys can warn us of harmful environmental conditions in and near our communities. We can return the favor by doing what we can to make the environ-

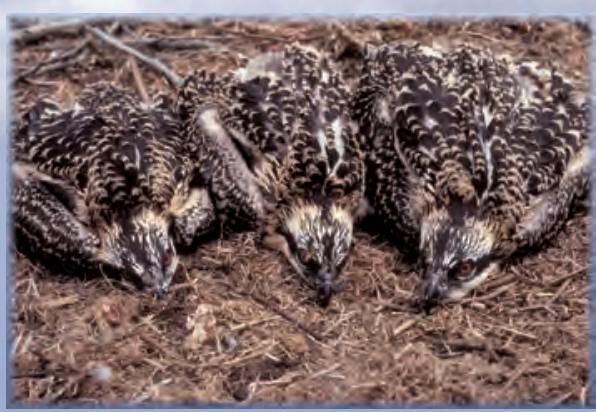

35-40 day-old ospreys ment safer for the birds - constructing and maintaining safe, appropriate nesting platforms, and keeping our waterways clean. This sort of coexistence between wildlife and humans contributes to our survival as well as that of other species on this planet.

For more information contact :
Charles J. Henny, James L. Kaiser,
or Robert A. Grove
USGS Forest and Rangeland
Ecosystem Science Center
3200 SW Jefferson Way
Corvallis, OR 97331
phone: 541-757-4840
fax: $541-757-4845$

\section{Suggested reading:}

Henny, C.J. and J.L. Kaiser. 1996. Osprey population increase along the Willamette River, Oregon, and the role of utility structures, 1976-1993. Pp 97-108 in: Raptors in Human Landscapes. Academic Press, London.

Henny, C.J., J.L. Kaiser, R.A. Grove, V.R. Bentley, J.E. Elliott. 2003. Biomagnification factors (fish to osprey eggs from the Willamette River, Oregon, U.S.A.) for PCDDs, PCDFs, PCBs and OC pesticides: Environmental Monitoring and Assessment, 84(3):275-315

Martell, M.S., C.J. Henny, P.E. Nye, and M.J. Solensky. 2001. Fall migration routes, timing, and wintering sites of North American ospreys as determined by satellite telemetry. Condor 103:715-724.

Poole, A.F. 1989. Ospreys: A Natural and Unnatural History. Cambridge University Press, Cambridge.

\section{Credits:}

Photos - Courtesy of Bruce Dishaw, Thad Furlong, Robert Grove, James Kaiser, and Michael Taft Editing — Miranda Ruth Graphic Design and Layout — Erik Ackerson 